\title{
Role of integrins in the metastatic spread of high-grade serous ovarian cancer
}

\author{
Slavomir Krajnak ${ }^{1}$ (D) Jörg Jäkel ${ }^{2} \cdot$ Katharina Anić $^{1} \cdot$ Roxana Schwab $^{1} \cdot$ Marcus Schmidt ${ }^{1}$. Annette Hasenburg ${ }^{1}$. \\ Wilfried Roth ${ }^{2} \cdot$ Walburgis Brenner $^{1} \cdot$ Marco Johannes Battista $^{1}$
}

Received: 24 July 2021 / Accepted: 11 October 2021 / Published online: 24 October 2021

(c) The Author(s) 2021

\begin{abstract}
Purpose Integrins may be involved in the metastatic spread of high-grade serous ovarian cancer (HGSOC) which determines the therapeutical approach and prognosis. We investigated the integrin expression in primary tumor and metastases of advanced HGSOC.

Methods The expression of integrin $\alpha 2, \alpha 4, \alpha 5, \alpha 6$, and $\beta 1$ was assessed by immunostaining in tumor samples of the ovary, omentum, and peritoneum of each patient. Differences in integrin expression among tumor localizations and their association with clinicopathological parameters were examined by Fisher's exact test. The impact of integrin expression on progressionfree survival (PFS) and overall survival (OS) was examined by Cox regression and Kaplan-Meier analyses.

Results Hundred and thirteen tumor samples of 40 HGSOC patients were examined. The expression of the integrins did not differ between the three tumor localizations (all $p$ values $>0.05$ ) with the exception of high expression of integrin $\alpha 4$ in primary tumor and omentum $(52.5 \%$ versus $47.5 \%, p=0.008)$ and primary tumor and peritoneum $(52.5 \%$ versus $47.5 \%$, $p=0.050$ ). High expression of integrin $\alpha 4$ in peritoneum was associated with poorer PFS (HR $2.0295 \%$ CI 1.01-4.05, $p=0.047)$, younger age $(p=0.047)$, and death $(p=0.046)$. Median PFS in patients with high expression of integrin $\alpha 4$ was 13.00 months, whereas median PFS in patients without high expression of integrin $\alpha 4$ was 21.00 months $(p=0.040)$. Expression of other integrins did not correlate with PFS or OS.

Conclusion Expression of integrin $\alpha 4$ may be altered during the metastatic spread of HGSOC and affect prognosis, whereas expression of integrin $\alpha 2, \alpha 5$, $\alpha 6$, and $\beta 1$ did not reveal any prognostic value.
\end{abstract}

Keywords Integrin $\cdot$ High-grade serous ovarian cancer $\cdot$ Metastatic spread $\cdot$ Immunostaining $\cdot$ Prognosis

\section{Introduction}

Ovarian cancer (OC) is one of the most commonly diagnosed cancers and the eighth leading causes of cancerrelated death among women, accounting for about 295 thousand new cases and 185 thousand deaths in 2018, worldwide [1]. Despite the increasing survival rates for all cancers collectively, the mortality in OC has improved only slightly in recent decades with a 5-year survival rate well below $50 \%$ [2]. OC is a heterogeneous disease consisting

Slavomir Krajnak

slavomir.krajnak@unimedizin-mainz.de

1 Department of Gynecology and Obstetrics, University Medical Center Mainz, Mainz, Germany

2 Department of Pathology, University Medical Center Mainz, Mainz, Germany of tumors differing in histopathology, immunochemistry, and molecular characteristics. High-grade serous ovarian cancer (HGSOC) is the most common histologic subtype, accounting for about $63 \%$ of epithelial OCs [3]. With the use of cytoreductive surgery and platinum-taxane-based chemotherapy, early stage disease is highly curable; however, the majority of patients presents with FIGO (Fédération Internationale de Gynécologie et d'Obstétrique) III/IV stage disease [2,3]. Moreover, $70-80 \%$ of patients with advanced OC experience disease recurrence after initial therapy [2, 4]. Therefore, there is an urgent need to identify potential prognostic biomarkers and novel therapeutic options to improve the outcome of our patients with HGSOC.

Cells of ovarian surface epithelium or fallopian tube undergoing malignant transformation alter their adhesion properties during the process of epidermal-mesenchymal transformation (EMT), which in turn results in the shedding 
of tumor cells into the peritoneal cavity floating in the peritoneal fluids until they find a secondary attachment site for further growth $[5,6]$. The surfaces of the peritoneal cavity, bowel, and omentum are the frequent sites for implantation of metastatic OC cells. The outer lining of these metastatic sites is comprised of a single layer of mesothelial cells, which express a variety of extracellular matrix (ECM) proteins, to which tumor cells can adhere before spreading $[7,8]$. Integrins, binding ECM proteins, such as laminin, fibronectin, and collagen, are heterodimeric adhesion receptors expressed on the cell surface that consist of a $\alpha$ subunit and a $\beta$ subunit. Thus far, $18 \alpha$ subunits and $8 \beta$ subunits of integrins have been identified, forming 24 different integrin heterodimers with different specificities $[9,10]$. Integrins generate an intracellular signal and, conversely, their functioning can be regulated by signals from inside the cell [9]. Integrin activation triggers a large variety of signal transduction events that modulate cell behaviors, such as adhesion, proliferation, survival or apoptosis, migration, and gene expression [11-14]. There are several studies, suggesting that integrins may play an important role in the metastatic spread of OC $[11,15,16]$.

This study aimed to investigate the immunohistochemical expression profile of integrin $\alpha 2, \alpha 4, \alpha 5, \alpha 6$, and $\beta 1$ at the primary tumor and the metastases of omentum and peritoneum in HGSOC patients and its prognostic value in the context of clinicopathological parameters, progression-free survival (PFS), and overall survival (OS).

\section{Materials and methods}

\section{Patients and tissue samples}

Patients with advanced HGSOC (FIGO IIIb-IV), who underwent primary surgery at our institution between 2004 and 2011, were included in the study, if paraffin-embedded tissue was available from the ovary and omentum or peritoneum. Clinicopathological and follow-up data until January 2019 were collected as previously reported by our group [17]. Tissue samples were provided by the tissue bank of the University Medical Center Mainz in accordance with the regulations of the tissue biobank and the approval of the Research Ethics Committee of the University Medical Center Mainz, Germany. For the analysis, all tissue samples were reassessed regarding histologic grade, histologic subtype, estrogen receptor (ER), progesterone receptor (PR), $\mathrm{Ki}-67$, and p53 expression. Informed consent was obtained from all patients, and all clinical investigations were conducted according to the ethical and legal standards.

\section{Immunostaining}

For immunostaining, 4- $\mu$ m-thick formalin-fixed and paraffin-embedded tumor sections were stained with following primary integrin antibodies: $\alpha 2$, clone C-9, sc-74466; $\alpha 4$, clone A-7, sc-365209 (both Santa Cruz Biotechnology Inc., Heidelberg, Germany); $\alpha 5$, NBP1-84576 (Novus Biologicals Bio-Techne Ltd, Wiesbaden, Germany); $\alpha 6$, HPA012696 (Sigma-Aldrich Inc., Darmstadt, Germany); and $\beta 1$, NBP216974 (Novus Biologicals Bio-Techne Ltd, Wiesbaden, Germany) according to the standard procedures. All the slides were analyzed using a Leica light microscope (Leica Microsystems Vertrieb Company, Wetzlar, Germany) by two of the authors (K.S. and J.J.). For the immunostaining analysis, we used a semiquantitative scoring method according to immunoreactive score (IRS) [18]. Each tissue sample was assessed by the intensity of immunostaining ( 0 , negative; 1 , weak; 2, moderate; 3, strong) (Fig. 1) and the area of positive cancer cells $(0$, negative; $1,1-10 \% ; 2,11-50 \% ; 3,51-80 \%$; $4,80-100 \%)$. The final score was calculated by multiplying the scores for staining intensity and area of positive cells. Cases with score 0 were considered as negative, whereas cases with score $\geq 1$ were considered as positive. In addition,
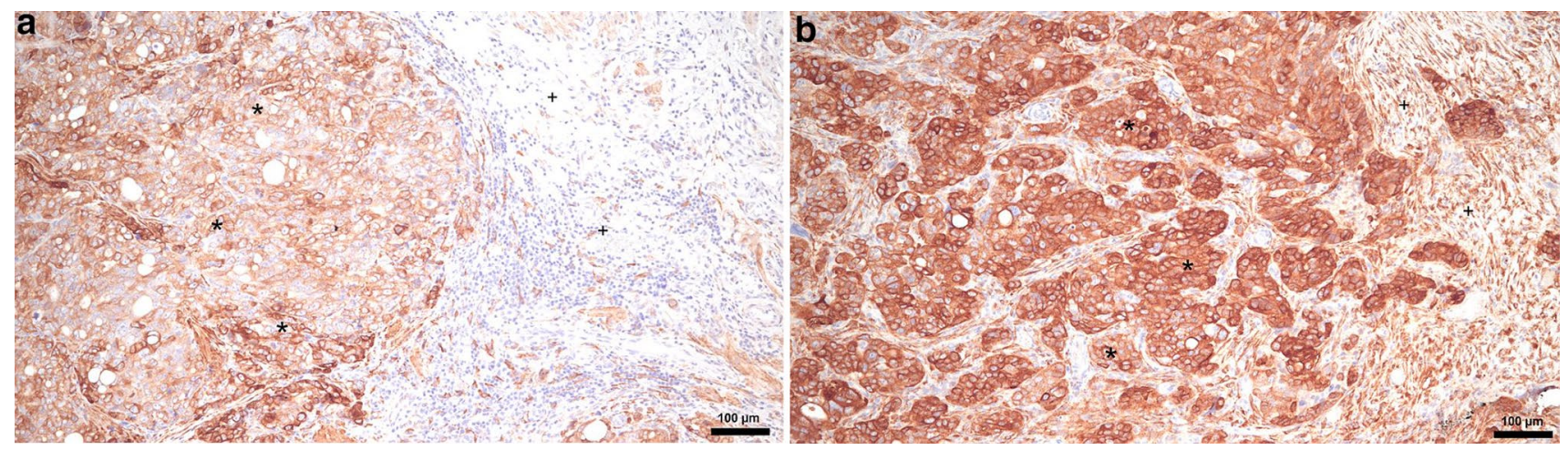

Fig. 1 Strong immunostaining of integrin $\alpha 4$ in the primary tumor (a) and peritoneal metastasis of serous cancer $(\mathbf{b}) .(*)$ Serous carcinoma cancer cells, (+) mesenchymal stromal cells 
scores from 0 to 4 were determined as low expression and scores from 5 to 12 as high expression.

\section{Statistical analyses}

Statistical analyses were performed using the SPSS statistical software program, version 26.0 (SPSS Inc., Chicago, IL, USA). Patient characteristics were analyzed descriptively. Differences in integrin expression among tumor localizations and their association with clinicopathological parameters were determined by Fisher's exact two-tailed test. The impact of integrin expression on PFS and OS was examined using Cox regression analyses and Kaplan-Meier estimator. In the Cox regression model, hazard ratio (HR) and $95 \%$ confidence interval (CI) was used. All tests were two-sided and a $p$ value of $<0.05$ was considered as statistically significant. As all analyses are explorative and not adjusted for multiple testing, the $p$ values should be interpreted with caution and in connection with the effect estimates.

\section{Results}

\section{Patient characteristics}

Between 2004 and 2011, a total of 134 patients with OC were screened in the Department of Gynecology and Obstetrics, University Medical Center Mainz, Germany (Fig. 2). 74 patients were excluded due to inappropriate histologic subtype, FIGO stage, or primary systemic treatment. 20 patients were excluded due to missing tissue samples or inappropriate follow-up information. Thereby, 40 advanced HGSOC patients with 113 tumor samples from the ovary, omentum, and peritoneum were analyzed. Patient characteristics are listed in Table 1. The median age was 63.9 years (range 31.7-78.3). At the time of first diagnosis, 31 (77.5\%) patients presented FIGO III and 9 (22.5\%) FIGO IV disease with a median tumor size of $5.0 \mathrm{~cm}$ (range 1.5-14.0). $10(25.0 \%)$ patients were node-negative, 13 (32.5\%) nodepositive, and in 17 (42.5\%) patients, lymph-node extirpation was not performed due to distant metastases (FIGO IV) or postoperative residual disease. Median Ki-67 expression was $50.0 \%$ (range 2.0-80.0). Complete surgical resection without macroscopic residual tumor was achieved in 15 (37.5\%) patients. 27 (67.5\%) patients completed adjuvant platinumbased chemotherapy; 7 (17.5\%) patients terminated the therapy early due to occurrence of unacceptable toxicity or poor general condition. At the time of analysis, 4 patients were alive and 3 patients without recurrence. The median PFS was 15.00 months (95\% CI 11.28-18.72); the median OS was 30.00 months (95\% CI 25.35-34.65).

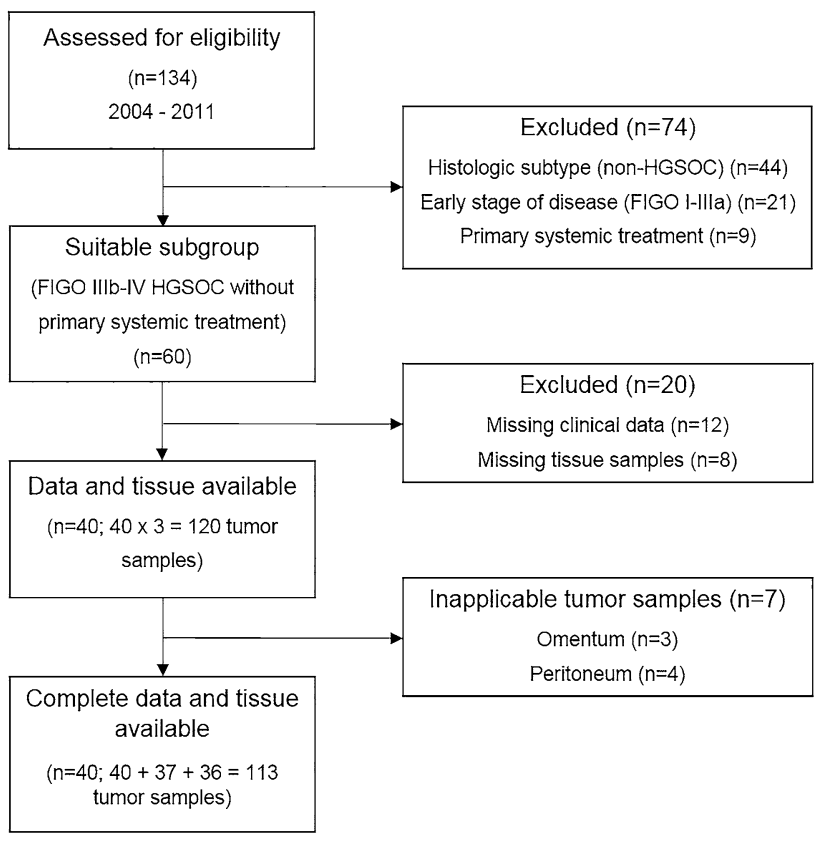

Fig. 2 Patient enrollment. FIGO Fédération Internationale de Gynécologie et d'Obstétrique, $H G S O C$ high-grade serous ovarian cancer

\section{Expression frequency of integrins}

The expression rate of integrins ranged from $57.5 \%$ (integrin $\beta 1$ in the omentum) to $95.0 \%$ (integrin $\alpha 4$ in the primary tumor), and did not differ between the three tumor localizations in most cases ( $p$ values $>0.05$ ) (Table 2). A significant difference in the expression of integrin $\beta 1$ was detected between primary tumor and omentum $(77.5 \%$ versus $57.5 \%, p=0.014)$. In addition, high expression of integrin $\alpha 4$ was observed less frequently in the omentum and peritoneum than in the primary tumor (both $47.5 \%$ versus $52.5 \%, p=0.008 ; p=0.050)$. High expression of integrin $\alpha 2$ was observed in $9(22.5 \%), 4(10.0 \%)$, and 4 $(10.0 \%)$ cases in the primary tumor, omentum, and peritoneum, respectively ( $p=0.244 ; p=0.163$ ). Integrin $\alpha 5, \alpha 6$, $\beta 1$ were highly expressed in a maximum of $4(10 \%)$ cases (integrin $\beta 1$ in the peritoneum).

Regarding age, high expression of integrin $\alpha 4$ occurred more frequently in younger patients (omentum, $p=0.007$; peritoneum, 0.047) (Table 3). Moreover, high expression of integrin $\alpha 4$ in peritoneum was observed more frequently in samples of deceased patients, whereas living patients did not show high expression of integrin $\alpha 4(p=0.046)$. However, the associations of integrin $\alpha 4$ expression with recurrence status, residual tumor burden, tumor size, tumor stage, nodal status, hormone receptor status, Ki-67, and p53 expression were not statistically significant (Table 3). In integrin $\alpha 2, \alpha 5, \alpha 6$, and $\beta 1$, Fisher's exact two-tailed test revealed no significant associations between integrin 
Table 1 Patient characteristics

\begin{tabular}{|c|c|}
\hline Characteristics & Patients $(n=40) n(\%)$ \\
\hline \multicolumn{2}{|l|}{ Age (years) } \\
\hline Median & 63.9 \\
\hline Range & $31.7-78.3$ \\
\hline \multicolumn{2}{|c|}{ Primary tumor size $(\mathrm{cm})$} \\
\hline Median & 5.0 \\
\hline Range & $1.5-14.0$ \\
\hline \multicolumn{2}{|l|}{ Tumor stage (FIGO) } \\
\hline I & $0(0.0)$ \\
\hline II & $0(0.0)$ \\
\hline III & $31(77.5)$ \\
\hline IIIa & $0(0.0)$ \\
\hline IIIb & $4(10.0)$ \\
\hline IIIc & $27(67.5)$ \\
\hline IV & $9(22.5)$ \\
\hline \multicolumn{2}{|l|}{ Nodal status } \\
\hline pNo & $10(25.0)$ \\
\hline pN1 & $13(32.5)$ \\
\hline LNE not performed & $17(42.5)$ \\
\hline \multicolumn{2}{|l|}{ Hormone receptor } \\
\hline \multicolumn{2}{|l|}{ ER } \\
\hline Positive & $36(90.0)$ \\
\hline Negative & $4(10.0)$ \\
\hline \multicolumn{2}{|l|}{ PR } \\
\hline Positive & $17(42.5)$ \\
\hline Negative & $23(57.5)$ \\
\hline \multicolumn{2}{|l|}{ p53 } \\
\hline Positive & $36(90.0)$ \\
\hline Negative & $3(7.5)$ \\
\hline Missing & $1(2.5)$ \\
\hline \multicolumn{2}{|l|}{ Ki-67 (\%) } \\
\hline Median & 50.0 \\
\hline Range & $2.0-80.0$ \\
\hline \multicolumn{2}{|c|}{ Postoperative residual tumor burden } \\
\hline Yes & $25(62.5)$ \\
\hline No & $15(37.5)$ \\
\hline \multicolumn{2}{|l|}{ Adjuvant chemotherapy } \\
\hline Complete & $27(67.5)$ \\
\hline Incomplete & $7(17.5)$ \\
\hline Missing & $6(15.0)$ \\
\hline \multicolumn{2}{|l|}{ Recurrence status } \\
\hline Recurrence & $37(92.5)$ \\
\hline Without recurrence & $3(7.5)$ \\
\hline \multicolumn{2}{|l|}{ Living status } \\
\hline Living & $4(10.0)$ \\
\hline Dead & $36(90.0)$ \\
\hline
\end{tabular}

$E R$ estrogen receptor, FIGO Fédération Internationale de Gynécologie et d'Obstétrique, $L N E$ lymph-node extirpation, $P R$ progesterone receptor expression and clinicopathological parameters (data not shown).

\section{Influence of integrins on survival}

Cox regression analyses showed that integrin $\alpha 4$ expression in peritoneum significantly correlated with PFS. High expression of integrin $\alpha 4$ in peritoneum was associated with poorer PFS (HR $2.0295 \%$ CI 1.01-4.05, $p=0.047$ ). HR for OS was 1.93 (95\% CI 0.96-3.89, $p=0.065$ ). No correlations between high expression of integrin $\alpha 4$ and PFS or OS were observed in the primary tumor (PFS, HR $1.4195 \%$ CI $0.74-2.70, p=0.297$; OS, HR $1.0095 \%$ CI $0.52-1.95$, $p=0.992$ ) and omentum (PFS, HR $1.1895 \%$ CI 0.60-2.33, $p=0.629$; OS, HR $1.1495 \%$ CI 0.57-2.27, $p$ 0.712). Expression of integrin $\alpha 2, \alpha 5, \alpha 6$, and $\beta 1$ did not correlate with PFS or OS (data not shown).

Kaplan-Meier analyses demonstrated significant associations between integrin $\alpha 4$ expression in peritoneum and PFS $(p=0.040)$ (Fig. 3), but not OS ( $p=0.060)$ (Fig. 4). Median PFS in patients with high expression of integrin $\alpha 4$ in peritoneum was 13.00 months (95\% CI 8.73-17.27); median PFS in patients without high expression of integrin $\alpha 4$ in peritoneum was 21.00 months (95\% CI 6.45-35.55). Median OS in patients with high expression of integrin $\alpha 4$ in peritoneum was 27.00 months (95\% CI 19.89-34.11); median $\mathrm{OS}$ in patients without high integrin $\alpha 4$ expression in peritoneum was 35.00 months (95\% CI 26.68-43.32). However, the associations of high expression of integrin $\alpha 4$ with PFS and OS were not statistically significant in primary tumor and omentum.

\section{Discussion}

In this explorative cohort study, we aimed to explore the role of various integrins in the metastatic spread in advanced HGSOC tumor samples. In most cases, the expression rate of integrins did not differ between the three tumor localizations and did not affect prognosis. However, integrin $\alpha 4$ appeared to be more frequently overexpressed in primary ovarian tumor samples than in omental and peritoneal metastases. Interestingly, the expression of integrin $\alpha 4$ may affect the prognosis, as shown in the Kaplan-Meier estimator and Cox regression analyses.

There are a plethora of studies investigating different integrins in OC. Contrary to our findings, Dötzer et al. [19] observed a high expression of integrin $\alpha 2 \beta 1$ in OC patients, which was identified as a marker for a poor prognosis with similar strength compared to FIGO stage and macroscopic residual tumor after surgery. High $\alpha 2 \beta 1$ expression in primary tumor was associated with a significant shorter PFS $(p=0.035)$ and platinum-free interval $(p=0.034)$. 
Table 2 Expression of integrin subunits regarding tumor localization

\begin{tabular}{|c|c|c|c|c|c|}
\hline \multirow{2}{*}{$\begin{array}{l}\text { Localization } \\
\text { Integrin } \\
\text { expression } n \\
(\%)\end{array}$} & \multirow{2}{*}{$\begin{array}{l}\text { Primary tumor } \\
\text { Positivity//High expression }\end{array}$} & \multirow{2}{*}{$\begin{array}{l}\text { Omentum } \\
\text { Positivity//High expression }\end{array}$} & \multirow{2}{*}{$\begin{array}{l}\text { Peritoneum } \\
\text { Positivity/High expression }\end{array}$} & \multicolumn{2}{|c|}{$\begin{array}{l}p \text { value } \\
\text { Primary tumor/Omentum//Pri- } \\
\text { mary tumor/Peritoneum }\end{array}$} \\
\hline & & & & Positivity & High expression \\
\hline$\alpha 2$ & $34(85.0 \%) / / 9(22.5 \%)$ & $31(77.5 \%) / / 4(10.0 \%)$ & $28(70.0 \%) / / 4(10.0 \%)$ & $0.245 / / 0.596$ & $0.244 / / 0.163$ \\
\hline$\alpha 4$ & $38(95.0 \%) / / 21(52.5 \%)$ & $35(87.5 \%) / / 19(47.5 \%)$ & $34(85.0 \%) / / 19(47.5 \%)$ & $0.107 / / 1.000$ & $0.008 / / 0.050$ \\
\hline$\alpha 5$ & $32(80.0 \%) / / 1(2.5 \%)$ & $26(65.0 \%) / / 1(2.5 \%)$ & $27(67.5 \%) / / 2(5.0 \%)$ & $0.352 / / 0.162$ & $1.000 / / 1.000$ \\
\hline$\alpha 6$ & $31(77.5 \%) / / 1(2.5 \%)$ & $33(82.5 \%) / / 1(2.5 \%)$ & $35(87.5 \%) / / 2(5.0 \%)$ & $0.198 / / 1.000$ & $1.000 / / 1.000$ \\
\hline$\beta 1$ & $31(77.5 \%) / / 0(0.0 \%)$ & $23(57.5 \%) / / 1(2.5 \%)$ & $28(70.0 \%) / / 4(10.0 \%)$ & $0.014 / / 0.384$ & N/A/N/A \\
\hline
\end{tabular}

Remarkably, in this study, a $\alpha 2 \beta 1$ expression $\geq 20 \%$ was determined as high, whereas our scoring used IRS leading to a different classification. Shield et al. [8] showed that enhanced expression of $\alpha 2 \beta 1$ integrin in OC cell lines (HEY [HGSOC] and OVHS-1 [ovarian clear cell adenocarcinoma]) grown as spheroids may influence spheroid disaggregation and proteolysis responsible for the peritoneal dissemination of OC. In addition, $\alpha 2 \beta 1$ integrin was shown to promote OC cell invasion by increasing matrix metalloproteinase (MMP)-2/MMP-9 activation, thereby disaggregating tumor cell spheroids and enhancing cell proliferation [20]. Integrin $\alpha 2 \beta 1$ was also shown to be involved in induction of chemoresistance in OC via phosphatidylinositol 3-kinase (PI3K)/ AKT signaling pathway [21]. Su et al. [22] isolated endothelial progenitor cells (EPCs) from OC patients, and demonstrated an increased integrin $\alpha 4$ expression, baseline migration, and adhesion mediated by the PI3K/AKT signaling pathway compared to those obtained from healthy subjects. Here, we reported for the first time that high expression of integrin $\alpha 4$ was significantly less frequent in the metastases of omentum and peritoneum than in the primary tumor. This may indicate that integrin $\alpha 4$ is involved in the metastatic spread of HGSOC. In addition, expression of integrin $\alpha 4$ showed associations with PFS, OS, and age at diagnosis. In particular, high expression of integrin $\alpha 4$ in peritoneum was significantly associated with poorer PFS and younger age. In a study with platinum-resistant mouse models, function-blocking antibodies directed against $\alpha 4 \beta 1$ sensitized advanced peritoneal disease to carboplatin and combination of integrin $\alpha 4 \beta 1$ blocking and carboplatin directly increased OC cell death [23]. Sawada et al. [24] evaluated the integrin $\alpha 5$ expression in 107 patients with FIGO II-IV advanced ovarian or peritoneal cancer. Each sample was scored based on the percentage of positive cells $(0, \leq 10 \% ; 1,10-25 \%$; $2,25-50 \% ; 3, \geq 50 \%)$ and the intensity of the staining $(0$, none; 1 , weak; 2 , strong). Only the samples which had strong staining of integrin $\alpha 5$ in $\geq 50 \%$ of tumor cells were considered as tumors overexpressing $\alpha 5$ integrin. In $9 \%$ of patients (7\% of HGSOC patients), overexpression of integrin $\alpha 5$ was detected with a median OS of 26 months versus 35 months in patients with low or negative integrin expression $(p=0.03)$. However, in our study, high expression of integrin $\alpha 5$ was detected only in one sample $(2.5 \%)$ of the primary tumor and omentum, respectively, and two samples (5.0\%) of peritoneum, and did not correlate with PFS or OS. In a study by Wei et al. [25], expression of integrin $\alpha 6$ was in tissues of chemoresistant OC patients higher than in those of chemosensitive OC patients $(60.0 \%$ versus $31.0 \%$, $\mathrm{p}<0.05)$. The intensity of immunostaining was graded as follows: 0 , weak; $1+$, moderate; $2+$, strong; and $3+$, very strong. The area of positive cancer cells was categorized as follows: $1+, 0-10 \% ; 2+, 11-50 \% ; 3+, 51-75 \%$; and $4+, 75-100 \%$. The score for each section was calculated by multiplying the scores for both the staining intensity and the area of positive cells. Scores of 0-3 were designated as low expression; scores of 4-12 were designated as high expression. Kaplan-Meier analyses revealed a significantly poorer OS ( $p=0.0008$, HR $0.8395 \%$ CI 0.73-0.95), but not PFS ( $p=0.30$, HR $0.9395 \%$ CI 0.82-1.06) associated with high integrin $\alpha 6$ expression in a cohort of 1,583 OC cases. In the present study, we used a similar scoring system and observed the expression of integrin $\alpha 6$ between 77.5 and $87.5 \%$. Despite this fact, we could not detect any correlations between integrin $\alpha 6$ expression and PFS or OS.

Taken together, several studies demonstrated that integrins may play an important role in the metastatic spread of OC. However, there is no convincing evidence of associations between integrins and prognosis in OC. Comparison of immunohistochemical studies is difficult, because different scoring systems and thresholds of high expression are used. Moreover, larger metastases may have already overgrown the primary site of cancer and peritoneal cell contact, limiting the assessment of the role of integrins at certain points in time.

A weakness of our study is the retrospective design; thus, the interpretation of the presented results is limited. 


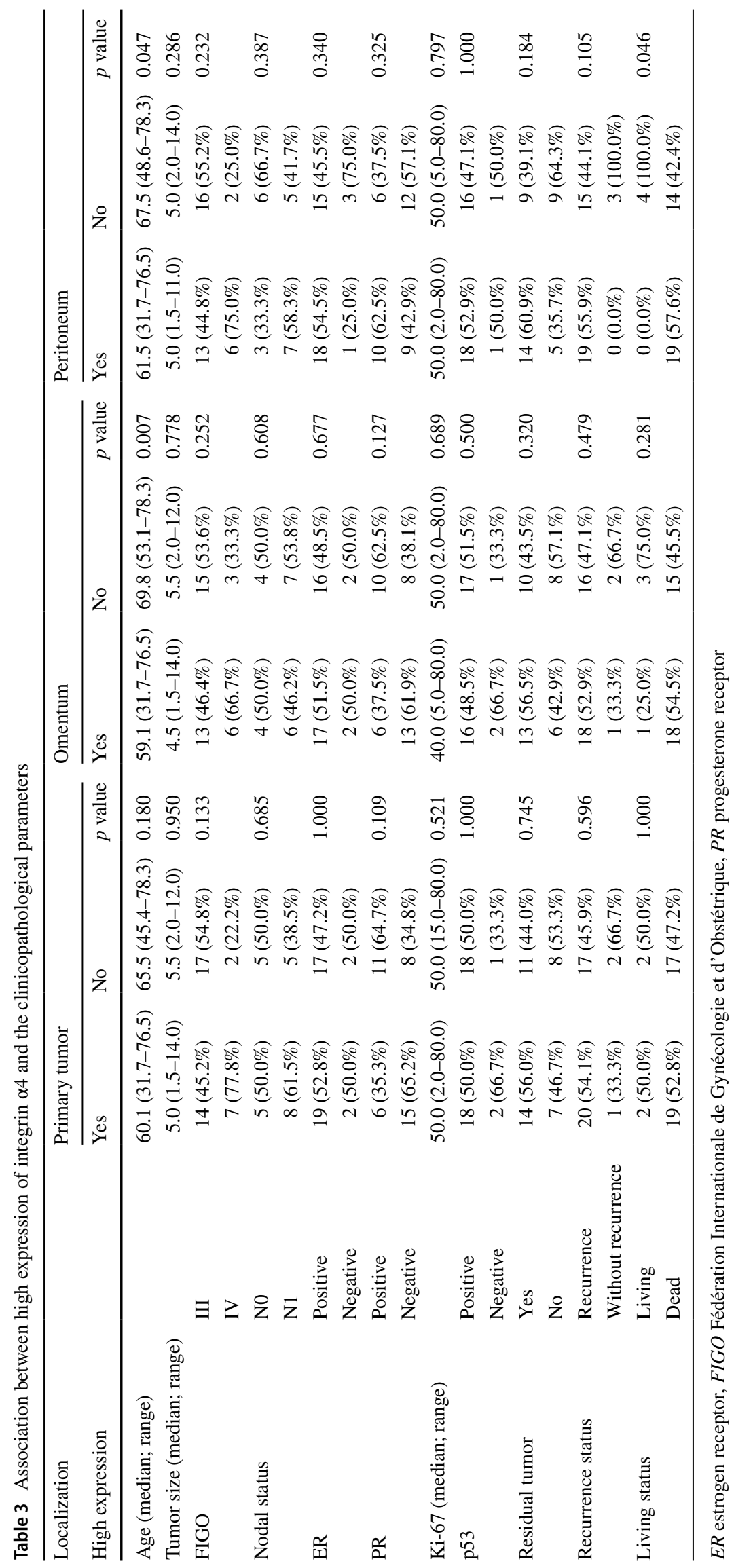




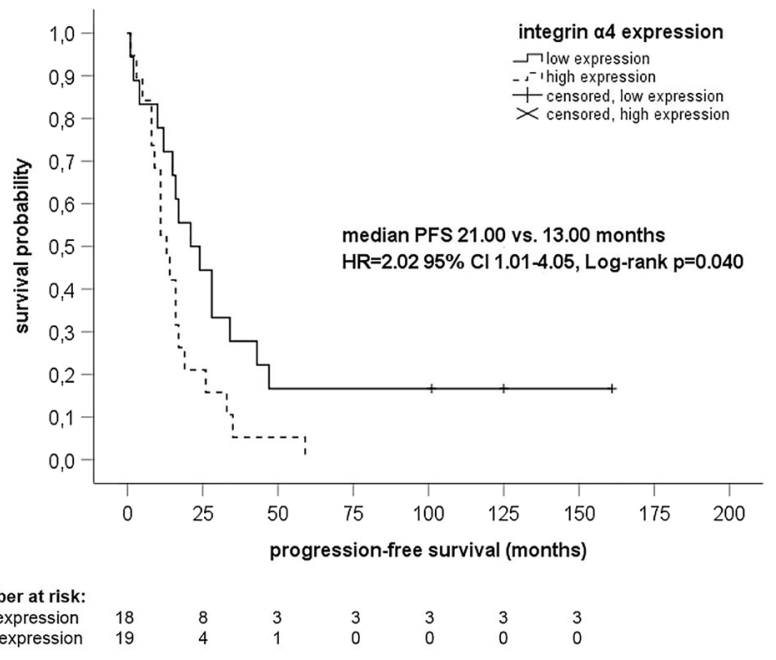

Fig. 3 Kaplan-Meier analysis of progression-free survival regarding expression of integrin $\alpha 4$ in peritoneum. $C I$ confidence interval, $H R$ hazard ratio, $P F S$ progression-free survival

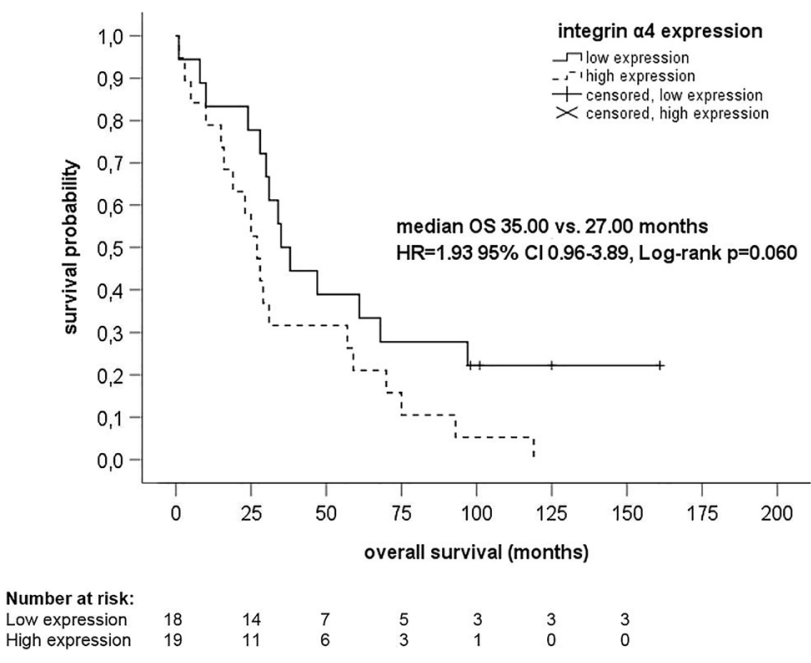

Fig. 4 Kaplan-Meier analysis of overall survival regarding expression of integrin $\alpha 4$ in peritoneum. $C I$ confidence interval, $H R$ hazard ratio, $O S$ overall survival

However, a strength is that we assessed the expression of integrins within a very homogenous group of advanced HGSOC in three different tumor localizations, allowing us to obtain a comprehensive picture of the spatial role of integrins in HGSOC.

In conclusion, the present study showed that expression of integrin $\alpha 4$ may be altered during the metastatic spread of HGSOC and affect prognosis. Moreover, we demonstrated that high expression of integrin $\alpha 4$ in peritoneum may be prognostically relevant. Expression of integrin $\alpha 2, \alpha 5, \alpha 6$, and $\beta 1$ did not reveal any prognostic value in HGSOC. These novel findings support further efforts to investigate $\alpha 4$ integrin in HGSOC.
Author contributions SK project development, data collection, data analysis, and manuscript writing/editing. JJ data collection, data analysis, and manuscript editing. KA data collection and manuscript editing. RS data collection and manuscript editing. MS supervision and manuscript editing. AH supervision and manuscript editing. WR supervision and manuscript editing. WB project development, data collection, data analysis, supervision, and manuscript editing. MJB project development, data collection, data analysis, supervision, and manuscript editing.

Funding Open Access funding enabled and organized by Projekt DEAL.

Data availability The datasets generated during the current study are available from the corresponding author on reasonable request.

Code availability Not applicable.

\section{Declarations}

Conflict of interest SK received speaker honoraria from Roche Pharma AG; research funding from Novartis and travel reimbursement from PharmaMar. MS received personal fees from AstraZeneca, Eisai, Lilly, MSD, Novartis, Pantarhei Bioscience, Pfizer, Roche, and SeaGen outside the submitted work; institutional research funding from AstraZeneca, BioNTech, Eisai, Genentech, German Breast Group, Novartis, Palleos, Pantarhei Bioscience, Pierre-Fabre, and Roche; and travel reimbursement from Pfizer and Roche. AH received personal fees from AstraZeneca, Celgen, GSK, LEO Pharma, MedConcept GmbH, Med update $\mathrm{GmbH}$, Medicultus, PharmaMar, Pfizer, Promedicis GmbH, Softconsult, Roche Pharma AG, Streamedup! GmbH, Tesaro Bio Germany GmbH. MJB received honoraria and travel reimbursement from Roche Pharma AG, Tesaro Bio GmbH, Glaxo Smith Kline, Clovis Oncology, Astra Zeneca, Pharma Mar GmbH, Celgene, Pierre-Fabre Pharma GmbH. All remaining authors have no conflicts of interest.

Ethical approval The study was approved by the Research Ethics Committee of the University Medical Center Mainz, Germany. Informed consent was obtained from all the patients, and all the clinical investigations were conducted according to the ethical and legal standards, and with the 1964 Helsinki Declaration and its later amendments.

Consent to participate Informed consent to participate in the study was obtained from all participants.

Consent for publication All participants consented to the publication of the study.

Open Access This article is licensed under a Creative Commons Attribution 4.0 International License, which permits use, sharing, adaptation, distribution and reproduction in any medium or format, as long as you give appropriate credit to the original author(s) and the source, provide a link to the Creative Commons licence, and indicate if changes were made. The images or other third party material in this article are included in the article's Creative Commons licence, unless indicated otherwise in a credit line to the material. If material is not included in the article's Creative Commons licence and your intended use is not permitted by statutory regulation or exceeds the permitted use, you will need to obtain permission directly from the copyright holder. To view a copy of this licence, visit http://creativecommons.org/licenses/by/4.0/. 


\section{References}

1. Bray F, Ferlay J, Soerjomataram I, Siegel RL, Torre LA, Jemal A (2018) Global cancer statistics 2018: GLOBOCAN estimates of incidence and mortality worldwide for 36 cancers in 185 countries. CA Cancer J Clin 68:394-424. https://doi.org/10.3322/caac. 21492

2. Lheureux S, Braunstein M, Oza AM (2019) Epithelial ovarian cancer: Evolution of management in the era of precision medicine. CA Cancer J Clin 69:280-304. https://doi.org/10.3322/caac.21559

3. Peres LC, Cushing-Haugen KL, Kobel M, Harris HR, Berchuck A, Rossing MA, Schildkraut JM, Doherty JA (2019) Invasive epithelial ovarian cancer survival by histotype and disease stage. $\mathrm{J}$ Natl Cancer Inst 111:60-68. https://doi.org/10.1093/jnci/djy071

4. Pignata S, Cecere CS, Du Bois A, Harter P, Heitz F (2017) Treatment of recurrent ovarian cancer. Ann Oncol 28:viii51-viii56. https://doi.org/10.1093/annonc/mdx441

5. Kurman RJ, Shih Ie M (2010) The origin and pathogenesis of epithelial ovarian cancer: a proposed unifying theory. Am J Surg Pathol 34:433-443. https://doi.org/10.1097/PAS.0b013e3181 cf3d79

6. Naora H, Montell DJ (2005) Ovarian cancer metastasis: integrating insights from disparate model organisms. Nat Rev Cancer 5:355-366. https://doi.org/10.1038/nrc1611

7. Lessan K, Aguiar DJ, Oegema T, Siebenson L, Skubitz AP (1999) CD44 and beta1 integrin mediate ovarian carcinoma cell adhesion to peritoneal mesothelial cells. Am J Pathol 154:1525-1537. https://doi.org/10.1016/s0002-9440(10)65406-5

8. Shield K, Riley C, Quinn MA, Rice GE, Ackland ML, Ahmed N (2007) Alpha2beta1 integrin affects metastatic potential of ovarian carcinoma spheroids by supporting disaggregation and proteolysis. J Carcinog 6:11. https://doi.org/10.1186/1477-3163-6-11

9. Hynes RO (2002) Integrins: bidirectional, allosteric signaling machines. Cell 110:673-687. https://doi.org/10.1016/s00928674(02)00971-6

10. Zhang K, Chen J (2012) The regulation of integrin function by divalent cations. Cell Adh Migr 6:20-29. https://doi.org/10.4161/ cam. 18702

11. Alday-Parejo B, Stupp R, Ruegg C (2019) Are integrins still practicable targets for anti-cancer therapy? Cancers (Basel) 11:978. https://doi.org/10.3390/cancers 11070978

12. Bianconi D, Unseld M, Prager GW (2016) Integrins in the spotlight of cancer. Int J Mol Sci 17:2037. https://doi.org/10.3390/ ijms 17122037

13. Lengyel E (2010) Ovarian cancer development and metastasis. Am J Pathol 177:1053-1064. https://doi.org/10.2353/ajpath.2010. 100105

14. Takada Y, Ye X, Simon S (2007) The integrins. Genome Biol 8:215. https://doi.org/10.1186/gb-2007-8-5-215

15. Kobayashi M, Sawada K, Kimura T (2017) Potential of integrin inhibitors for treating ovarian cancer: a literature review. Cancers (Basel) 9:83. https://doi.org/10.3390/cancers9070083
16. Nieberler M, Reuning U, Reichart F, Notni J, Wester HJ, Schwaiger M, Weinmuller M, Rader A, Steiger K, Kessler H (2017) Exploring the role of RGD-recognizing integrins in cancer. Cancers (Basel) 9:116. https://doi.org/10.3390/cancers9090116

17. Battista MJ, Schmidt M, Jakobi S, Cotarelo C, Almstedt K, Heimes AS, Makris GM, Weyer V, Lebrecht A, Hoffmann G, Eichbaum M (2016) c-met is overexpressed in type I ovarian cancer: results of an investigative analysis in a cohort of consecutive ovarian cancer patients. Oncol Lett 12:2001-2007. https://doi.org/ 10.3892/ol.2016.4895

18. Remmele W, Stegner HE (1987) Recommendation for uniform definition of an immunoreactive score (IRS) for immunohistochemical estrogen receptor detection (ER-ICA) in breast cancer tissue. Pathologe 8:138-140

19. Dotzer K, Schluter F, Koch FEV, Brambs CE, Anthuber S, Frangini S, Czogalla B, Burges A, Werner J, Mahner S, Mayer B (2021) Integrin alpha2beta1 represents a prognostic and predictive biomarker in primary ovarian cancer. Biomedicines 9:289. https:// doi.org/10.3390/biomedicines9030289

20. Naci D, Vuori K, Aoudjit F (2015) Alpha2beta1 integrin in cancer development and chemoresistance. Semin Cancer Biol 35:145153. https://doi.org/10.1016/j.semcancer.2015.08.004

21. Zheng W, Ge D, Meng G (2020) Reversing microtubule-directed chemotherapeutic drug resistance by co-delivering alpha2beta1 inhibitor and paclitaxel with nanoparticles in ovarian cancer. Cell Biol Int 44:610-620. https://doi.org/10.1002/cbin.11261

22. Su Y, Zheng L, Wang Q, Bao J, Cai Z, Liu A (2010) The PI3K/Akt pathway upregulates Id 1 and integrin alpha4 to enhance recruitment of human ovarian cancer endothelial progenitor cells. BMC Cancer 10:459. https://doi.org/10.1186/1471-2407-10-459

23. Scalici JM, Harrer C, Allen A, Jazaeri A, Atkins KA, McLachlan KR, Slack-Davis JK (2014) Inhibition of alpha4beta1 integrin increases ovarian cancer response to carboplatin. Gynecol Oncol 132:455-461. https://doi.org/10.1016/j.ygyno.2013.12.031

24. Sawada K, Mitra AK, Radjabi AR, Bhaskar V, Kistner EO, Tretiakova M, Jagadeeswaran S, Montag A, Becker A, Kenny HA, Peter ME, Ramakrishnan V, Yamada SD, Lengyel E (2008) Loss of E-cadherin promotes ovarian cancer metastasis via alpha 5-integrin, which is a therapeutic target. Cancer Res 68:2329-2339. https://doi.org/10.1158/0008-5472.CAN-07-5167

25. Wei L, Yin F, Chen C, Li L (2019) Expression of integrin alpha-6 is associated with multi drug resistance and prognosis in ovarian cancer. Oncol Lett 17:3974-3980. https://doi.org/10.3892/ol. 2019.10056

Publisher's Note Springer Nature remains neutral with regard to jurisdictional claims in published maps and institutional affiliations. 